\title{
ORGANIZAÇÃO DA COMUNIDADE E ESTRUTURA FILOGENÉTICA DO COMPONENTE ARBÓREO DE UM FRAGMENTO DE FLORESTA NEBULAR NO PLANALTO CATARINENSE
}

\author{
COMMUNITY ORGANIZATION AND PHYLOGENETIC STRUCTURE OF THE TREE \\ COMPONENT OF A NEBULAR FOREST FRAGMENT IN 'PLANALTO CATARINENSE' REGION, \\ SOUTHERN BRAZIL
}

\begin{abstract}
Ana Carolina da Silva ${ }^{1}$ Pedro Higuchi ${ }^{2}$ Marcos Eduardo Guerra Sobral ${ }^{3}$ Marcelo Negrini ${ }^{4}$
Fernando Buzzi Júnior ${ }^{4}$ Marco Antônio Bento ${ }^{4}$ André Leonardo da Silva ${ }^{4}$

Amanda Koche Marcon ${ }^{5}$ Tiago de Souza Ferreira ${ }^{6}$ Bruna Salami ${ }^{5} \quad$ Angélica Dalla Rosa $^{7}$
\end{abstract}

\section{RESUMO}

O presente estudo teve como objetivos conhecer a organização da comunidade e a estruturação filogenética do componente arbóreo de um fragmento de Floresta Nebular em Urubici - SC. Para isso, foram alocadas 25 parcelas de $400 \mathrm{~m}^{2}$, nas quais foi medida a circunferência a altura do peito - CAP, e identificadas todas as árvores com CAP igual ou superior a $15,7 \mathrm{~cm}$. Foram calculados o índice de diversidade de ShannonWiener e os descritores fitossociológicos. A síndrome de dispersão de propágulos e a distribuição espacial de cada espécie foram determinadas. A estruturação filogenética foi avaliada por meio dos valores de Mean pairwise distance (MPD) e de Net Relatedness Index (NRI), calculados a partir de uma árvore filogenética construída em função das espécies amostradas, de uma matriz de abundância das espécies por parcelas e 1.000 simulações de uma comunidade organizada filogeneticamente de forma aleatória. A estruturação espacial das métricas filogenéticas foi analisada por meio do Índice I de Moran. Foram amostrados 1.579 indivíduos, pertencentes a 33 espécies, sendo Myrtaceae a família de maior riqueza de espécies. O baixo valor de diversidade $(2,43)$, associado à baixa riqueza na área, é esperado em Florestas Nebulares, cujo ambiente é tipicamente seletivo. A maior representação na floresta foi de Myrceugenia euosma (O.Berg) D.Legrand $(\mathrm{VI}=24,51 \%)$. A síndrome de dispersão predominante foi a zoocoria $(84,85 \%)$, seguida pela anemocoria $(15,15 \%)$, e a distribuição espacial foi predominantemente agregada. A comunidade apresentou variação em relação à estruturação filogenética, sendo que, para a maioria das parcelas, o padrão não diferiu do modelo nulo de completa aleatoriedade.

Palavras-chave: Floresta com Araucária; Floresta Ombrófila Mista Alto-montana; comunidade arbórea; filogenia.

1 Engenheira Florestal, Dr $^{\mathrm{a}}$., Professora do Departamento de Engenharia Florestal, Universidade do Estado de Santa Catarina. Av. Luiz de Camões, 2090, CEP 88520-000, Lages (SC), Brasil. carol_sil4@yahoo.com.br

2 Engenheiro Florestal, Dr., Professor do Departamento de Engenharia Florestal, Universidade do Estado de Santa Catarina. Av. Luiz de Camões, 2090, CEP 88520-000, Lages (SC), Brasil. higuchip@gmail.com

3 Biólogo, Dr., Professor do Departamento de Ciências Naturais, Universidade Federal de São João Del-Rei. Pç. Dom Helvécio, 74, CEP 36301-160, São João Del-Rei (MG), Brasil. marcos_sobral@hotmail.com

4 Engenheiro Florestal, Departamento de Engenharia Florestal, Universidade do Estado de Santa Catarina. Av. Luiz de Camões, 2090, CEP 88520-000, Lages (SC), Brasil. engfmarcelonegrini@hotmail.com/ buzzifjr@hotmail.com/marco_a_bento@hotmail.com/andreleofloresta@gmail.com

5 Engenheira Florestal, MSc., Departamento de Engenharia Florestal, Universidade do Estado de Santa Catarina. Av. Luiz de Camões, 2090, CEP 88520-000, Lages (SC), Brasil. amandamarcon@yahoo.com.br/ brunaflorestal@yahoo.com.br

6 Engenheiro Florestal, MSc., Departamento de Engenharia Florestal, Universidade do Estado de Santa Catarina. Av. Luiz de Camões, 2090, CEP 88520-000, Lages (SC), Brasil. tiagoferreira@florestal.eng.br

7 Engenheira Florestal, Departamento de Engenharia Florestal, Universidade do Estado de Santa Catarina. Av. Luiz de Camões, 2090, CEP 88520-000, Lages (SC), Brasil. angelica.dalla.rosa@hotmail.com

Recebido para publicação em 18/08/2013 e aceito em 19/06/2015

Ci. Fl., v. 27, n. 1, jan.-mar., 2017 


\section{ABSTRACT}

This study aimed to survey the community organization and the phylogenetic structure of tree species component in a nebular forest, in the municipality of Urubici, Santa Catarina state. A total of 25 plots $\left(400 \mathrm{~m}^{2}\right)$ were allocated, where all trees with circumference at breast height (cbh) equal or superior than $15.7 \mathrm{~cm}$ were measured (cbh) and identified. The Shannon index and phytosociological descriptors were determined. The dispersal syndromes of propagules were determined and the spatial distribution of each species was analyzed. The phylogenetic structure was evaluated by the values of 'Mean Pairwise Distance' (MPD) and Net Relatedness Index (NRI), determined through a phylogenetic tree built in function of the species sampled, an abundance matrix of species by plots and 1,000 simulations of a community with phylogenetic randomness organization. The spatial structure of the phylogenetic metrics was analyzed through I Moran Index. A total of 1,579 trees were sampled, belonging to 33 species, with Myrtaceae as the richest family. The low value of diversity (2.43), associated to low richness, is expected for nebular forest, where the environment is typically selective. The most representative species in the forest was Myrceugenia euosma (O.Berg) D.Legrand ( $\mathrm{VI}=24.51 \%)$. The predominant dispersal syndrome was zoochory $(84.85 \%)$, followed by anemochory (15.15\%); and the species showed predominantly a clustered spatial distribution. The community had variation in relation to the phylogenetic structure, with most plots showing no significant difference from the null model of complete randomness.

Keywords: Araucaria Forest; Upper-montane Araucaria Forest; tree community; phylogeny.

\section{INTRODUÇÃO}

No Brasil, as Florestas Nebulares (FNs) ocorrem em áreas de elevada altitude, restritas ao alto das principais cadeias de montanhas, por isso, não apresentando grande extensão geográfica. No Estado de Santa Catarina, existem dois núcleos deste tipo florestal, um ao norte, associado à Serra do Mar, e outro ao sul, associado à Serra Geral (KLEIN, 1978). Do ponto de vista climático, destacam-se nestas áreas as baixas temperaturas e a nebulosidade constante, o que tornam estes locais bastante seletivos e com muitas espécies exclusivas, adaptadas para sobreviver em tais condições. Estudos filogeográficos sugerem que durante as flutuações climáticas do Quaternário, as áreas nebulares podem ter desempenhado importante função como refúgios ecológicos na região, por ocuparem microssítios favoráveis, com maior umidade (CARNAVAL; MORITZ, 2008).

Por apresentarem uma composição florística peculiar (HIGUCHI et al. 2012a), resultado da interação de fatores históricos e ecológicos, e por serem locais em que nascem os principais rios do estado, essas áreas são consideradas como estratégicas para a conservação. No entanto, assim como as demais formações florestais brasileiras, as FNs apresentam um longo histórico de perturbação antrópica e fragmentação. A pecuária extensiva, com a entrada de animais no interior dos fragmentos, principalmente no inverno, quando os animais procuram abrigo e maior oferta de alimento, é uma prática tradicional e comum na região, com o potencial de limitar a regeneração natural das espécies, devido ao pisoteio. O status de conservação destas áreas pode tornar-se ainda mais crítico, se for considerado o cenário de mudanças climáticas, por meio do aquecimento global. Segundo as previsões do Painel Intergovernamental sobre Mudanças Climáticas da ONU (IPCC), até 2100, a temperatura global da superfície terrestre aumentará entre $1,1 \mathrm{a} 6,4^{\circ} \mathrm{C}$ (INTERGOVERNMENTAL PANEL ON CLIMATE CHANGE, 2007). Uma das respostas imediatas das espécies a estas mudanças climáticas seria o deslocamento em direção ao sul ou a maiores altitudes (COWEL et al., 2008), com o propósito de ajuste do nicho termal. No entanto, para espécies vegetais endêmicas de áreas nebulares, este ajuste via deslocamento espacial é limitado, uma vez que essas já estão "ilhadas" nos pontos de maior elevação altitudinal, o que torna as FNs um ambiente extremamente frágil no contexto de mudanças climáticas. Desta forma, justificam-se estudos ecológicos dessas, com o propósito de melhor conhecer a diversidade existente e subsidiar futuras estratégias de conservação.

Apesar de alguns estudos florísticos ou fitossociológicos em florestas terem sido realizados na região (FORMENTO et al., 2004; KLAUBERG et al., 2010; NASCIMENTO et al., 2011; AGUIAR et al., 2012; HIGUCHI et al., 2012a; 2012b; SILVA et al., 2012; 2013), pouco se conhece sobre a ecologia de florestas nebulares do Planalto Catarinense, destacando-se o estudo de Falkenberg (2003), Eskuche 
(2007), Higuchi et al. (2013) e Marcon et al. (2014). Dos estudos realizados, os que avaliam a distribuição das espécies ao longo de gradientes ambientais, baseiam-se, predominantemente, na teoria clássica de nichos ecológicos. No entanto, o avanço no conhecimento sobre a filogenia das espécies e novos recursos computacionais têm permitido análises sob uma abordagem evolutiva (CAVENDER-BARES et al., 2009), que aumentou as possibilidades de inferências ecológicas, com destaque para o entendimento dos processos que determinam a organização de comunidades (HARDY, 2008). Fatores como a competição, a herbivoria e os fitopatógenos podem controlar a população não apenas de indivíduos da mesma espécie, mas também de grupos filogeneticamente semelhantes, resultando em dispersão filogenética, de forma que espécies ou indivíduos seriam mais distantes filogeneticamente entre si, do que o esperado em uma comunidade organizada de forma aleatória (WEBB et al., 2002; KEMBEL; HUBBELL, 2006). Por outro lado, a existência de um filtro ambiental poderia resultar em agrupamento filogenético de espécies ou indivíduos, a partir da seleção de um grupo filogeneticamente próximo, com exigências ecológicas semelhantes (WEBB et al., 2002; KEMBEL; HUBBELL, 2006). Já uma estrutura filogenética aleatória poderia ocorrer devido a vários fatores como, por exemplo, no caso de equilíbrio entre as forças ecológicas que moldam a estrutura da comunidade (KEMBEL; HUBBELL, 2006).

Diante desse contexto, os objetivos do presente trabalho foram: i) conhecer a organização da comunidade arbórea de um fragmento de floresta nebular no Planalto Catarinense, determinando-se sua composição florístico-estrutural, assim como identificar as estratégias de dispersão de propágulos e a distribuição espacial das espécies arbóreas encontradas no fragmento estudado; e ii) conhecer a estruturação filogenética da comunidade em pequena escala espacial. As hipóteses do trabalho são que: i) a comunidade arbórea apresenta a composição florística e a estrutura típica de uma floresta nebular, porém, com influência de elementos planálticos presentes na Floresta Ombrófila Mista, na qual está inserida; ii) as populações arbóreas apresentam predominância de zoocoria e, associado a isto, padrão de distribuição espacial agregada; iii) a comunidade apresenta diferentes padrões de estruturação filogenética entre as parcelas, que pode ocorrer em função da complexa interação entre as forças ecológicas dominantes (e.g. filtro ambiental, competição).

\section{MATERIAL E MÉTODOS}

\section{Caracterização da área de estudo}

Foi estudado um fragmento de Floresta Nebular localizado no Planalto Catarinense no município de Urubici - SC. O planalto catarinense está localizado na porção central do Estado e é formado por relevo que apresenta grande variação, ocorrendo desde relevo montanhoso a suave ondulado, com altitudes oscilando de 700 a mais de $1.800 \mathrm{~m}$ acima do nível do mar, e com um gradiente altitudinal declinando no sentido LesteOeste. O fragmento estudado possui as coordenadas de $28^{\circ} 04^{\prime} 27^{\prime \prime}$ na latitude Sul e $49^{\circ} 37^{\prime} 30^{\prime \prime}$ na longitude Oeste, possuindo altitude aproximada de $1.600 \mathrm{~m}$. A região possui clima $\mathrm{Cfb}$, de acordo com a classificação de Köppen e, de acordo com base de dados do Wordclim (HIJMANS et al., 2005), com resolução de 1 km, para o período de 1950 a 2000, a precipitação média anual foi de $1.753 \mathrm{~mm}$ e a temperatura média anual foi de $12,7^{\circ} \mathrm{C}$, sendo que as temperaturas baixas do inverno permitem a ocorrência de geadas e neve. A vegetação desta região é formada por um mosaico de campos e Floresta Ombrófila Mista Alto-Montana (IBGE, 2012). Assim, as áreas de floresta são descontínuas, formando fragmentos naturais na paisagem. Como destacado por Koehler et al. (2002), o clima de áreas montanhosas desempenha forte influência sobre a composição florística e a estrutura do componente arbóreo. As áreas mais elevadas são comumente caracterizadas por temperaturas baixas, principalmente durante a noite, sendo também comum a formação de nuvens, o que caracteriza um ambiente nebular, com menor incidência de radiação solar e elevada umidade relativa do ar, o que conduz a uma baixa capacidade evapotranspirativa que, associada à predominância de solos pouco profundos, reflete em um ambiente ecologicamente seletivo.

\section{Desenho amostral e coleta de dados}

O local foi objetivo de estudo de Marcon et al. (2014), que avaliou a influência das variáveis 
ambientais sobre a organização florístico-estrutural na mesma área. Assim, foram alocadas, de forma sistemática na área do fragmento, 25 parcelas de $400 \mathrm{~m}^{2}$ cada $(20 \times 20 \mathrm{~m})$, totalizando 1 ha amostrado. Em cada parcela foram coletados, identificados, marcados com plaquetas de alumínio e medidos com uma fita métrica todos os indivíduos arbóreos vivos que apresentaram circunferência a altura do peito (CAP), medida a $1,30 \mathrm{~m}$ do solo, igual ou superior a $15,7 \mathrm{~cm}$ (DAP $\geq 5 \mathrm{~cm}$ ). Indivíduos arbóreos com troncos múltiplos foram medidos quando a raiz da soma dos quadrados dos CAPs foi maior ou igual a $15,7 \mathrm{~cm}$. As identificações foram realizadas por meio de comparações em literatura especializada e por especialistas. As espécies foram classificadas nas famílias de acordo com o sistema APG III (ANGIOSPERM PHYLOGENY GROUP, 2009). Portanto, a partir da lista florística obtida por Marcon et al. (2014), realizou-se as análises do presente estudo.

\section{Análise dos dados}

A suficiência amostral para determinar a riqueza de espécies nas parcelas foi analisada por meio da elaboração da curva de acumulação de espécies, construída por meio do método de aleatorização, com 1.000 permutações. A distribuição dos valores de riqueza estimados para as unidades amostrais, por meio das permutações, foi inserida na curva de acumulação de espécies, utilizando gráficos do tipo boxplot. ): Este procedimento foi realizado por meio da linguagem de programação estatística R (R CORE TEAM, 2012) e a biblioteca Vegan (OKSANEN et al., 2009).

Para a quantificação da diversidade, foi calculado o índice de Shannon-Wiener (H'), além da determinação da equabilidade de Pielou (J') para o conhecimento da dominância ecológica na área (ZAR, 1996). Os descritores fitossociológicos foram calculados segundo Mueller-Dombois e Ellemberg (1974): densidade absoluta, frequência absoluta, dominância absoluta expressa pela área basal, densidade relativa, frequência relativa, dominância relativa e valor de importância (VI). A síndrome de dispersão de propágulos de cada espécie encontrada no fragmento foi definida de acordo com a metodologia de Van der Pijl (1982), em que: i) espécies de frutos carnosos e com outros elementos que evidenciam a dispersão por animais, foram consideradas como dispersão zoocórica; ii) frutos ou sementes com alas e mecanismos para flutuação, foram definidos como dispersão anemocórica; iii) frutos tipo cápsula deiscente que, ao se abrir, liberam as sementes por um rápido movimento, foram considerados dispersão autocórica. A determinação dessas síndromes se deu por observações dos diásporos e por consultas em literatura (RONDON NETO et al., 2001; BUDKE et al., 2005; GIEHL et al., 2007; ALMEIDA et al., 2008; LEYSER et al., 2009; NEGRINI et al., 2012). Para a verificação da distribuição espacial das espécies na área foi calculado, para cada população das espécies amostradas nas parcelas (população com no mínimo dez indivíduos), o índice de Morisita (MORISITA, 1962) modificado por Smith-Gill (1975): Índice de Morisita Padronizado. Neste índice, se o valor padronizado é maior que 0,5 , a distribuição espacial da população é agregada, se é menor que $-0,5$, a distribuição é uniforme, se está entre esses dois valores, é aleatória.

A partir das espécies amostradas na comunidade, foi criada uma árvore filogenética, representando o pool de espécies que podem ocorrer em cada uma das parcelas, por meio do programa on-line PHYLOMATIC 3 (WEBB; DONOGHUE, 2004), disponível em $<$ http://phylodiversity.net/phylomatic/>, utilizando a "superárvore" filogenética R20120829. Para isto, foi elaborada uma lista com todas as espécies amostradas no estudo, organizada na forma família/gênero/espécies, que posteriormente foi importada no site indicado acima, no espaço destinado aos táxons. A árvore filogenética criada foi importada para o programa PHYLOCOM 4.1. (WEBB et al., 2008), no qual os comprimentos dos "ramos" foram ajustados utilizando o algoritmo BLADJ, em função das idades dos clados, em milhões de anos, fornecidos por Gastauer e Meira Neto (2013), baseado no trabalho de Wikström et al. (2001). Em seguida, foram calculadas as seguintes medidas de diversidade filogenética para cada parcela, considerando os dados de abundância: i) "Mean phylogenetic distance" (MPD), para quantificar as relações filogenéticas dos indivíduos em cada parcela, por meio da distância média entre todos os pares de indivíduos; e ii) "Net relatedness index" (NRI), que compara o valor de MPD observado nas parcelas com o valor de MPD esperado para uma comunidade completamente aleatória, calculado 1.000 vezes, a partir da retirada randômica de espécies do pool local (WEBB et al., 2008). Se os valores NRI foram positivos e, nas simulações de comunidades aleatórias, os MPDs observados foram inferiores aos MPDs simulados por 975 vezes, considerou-se a 
ocorrência de agrupamento filogenético $(p<0,05)$. Se os valores NRI foram negativos e, por 975 vezes, os MPDs observados foram superiores aos MPDs simulados, considerou-se a ocorrência de dispersão filogenética $(p<0,05)($ WEBB, 2000). A estruturação espacial das métricas filogenéticas foi avaliada por meio de correlogramas baseados no índice estatístico I de Moran, com alisamento por spline (MORAN, 1950). Envelopes indicativos de ausência de autocorrelação foram construídos por meio da técnica de bootstrap, a partir de 1.000 reamostragens. Os valores de I Moran variam de -1 a 1, os valores positivos indicam associação espacial positiva entre os locais (similaridade) e valores negativos indicam associação negativa (dissimilaridade). Valores em torno de 0 , dentro dos envelopes de completa aleatoriedade, indicam distribuição aleatória sem associação espacial.

\section{RESULTADOS E DISCUSSÃO}

Foram amostrados 1.579 indivíduos dentro das parcelas, distribuídos em 19 famílias, 26 gêneros e 33 espécies. A curva de acumulação de espécies indicou uma amostragem adequada (Figura 1), sendo que houve um aumento de apenas $0,67 \%$ no número de espécies com a inclusão da última parcela, com a curva tendendo à estabilização. $\mathrm{O}$ índice de diversidade $\left(\mathrm{H}^{\prime}=2,43\right)$, associado à baixa riqueza na área (35 espécies arbóreas), é esperado em Florestas Nebulares, nas quais o ambiente seleciona poucas espécies. Resultados similares foram encontrados em outros estudos em ambientes similares, como de Higuchi et al. (2013).

A árvore filogenética representada pelas espécies amostradas nas parcelas (33) apresentou uma distância média dos ramos de 53,92 milhões de anos (Figura 2). As espécies mais basais foram a pteridófita Dicksonia sellowiana e a gimnosperma Araucaria angustifolia. O clado de maior riqueza foi Malvídeas com 12 espécies, sendo Myrtaceae a família mais representativa (11), seguida de Asterídeas II, com 10 espécies, com Asteraceae e Aquifoliaceae se destacando, cada uma com duas espécies.

O gênero de maior riqueza foi Myrceugenia (Myrtaceae), com sete espécies, que corresponde a $22 \%$ das espécies amostradas, ocupando ramos curtos da árvore filogenética, indicando diversificação mais recente. Myrtaceae é uma das maiores famílias da flora brasileira (SOUZA; LORENZI, 2005), além de, geralmente, ser a família de maior riqueza de espécies arbóreas na Floresta Ombrófila Mista, conforme demonstrado em outros estudos, como os de Jarenkow e Batista (1987), Nascimento et al. (2001), Higuchi et al. (2012a; 2012b) e Silva et al. (2012). Além disso, normalmente é a família de maior riqueza arbórea também em Floresta Ombrófila Mista Alto-Montana, como demonstrado no estudo de Higuchi et al. (2013). É comum o gênero Myrceugenia se destacar nesse tipo de formação florestal estudada. Outros autores,

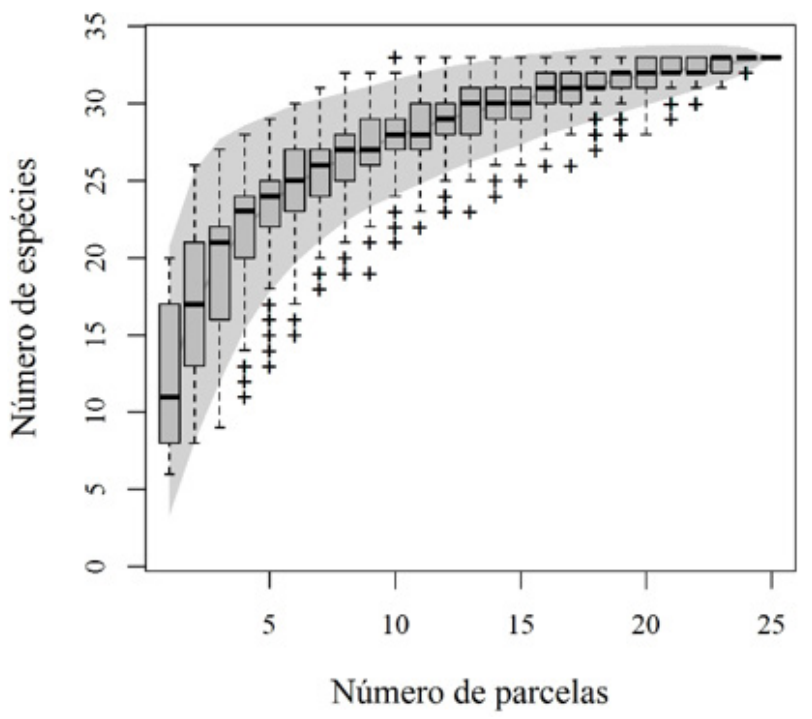

FIGURA 1: Curva de acumulação de espécie do componente arbóreo de um remanescente de Floresta Nebular em Urubici - SC.

FIGURE 1: Tree species accumulation curve of a Nebular Forest remnant, in the municipality of Urubici, SC state. 


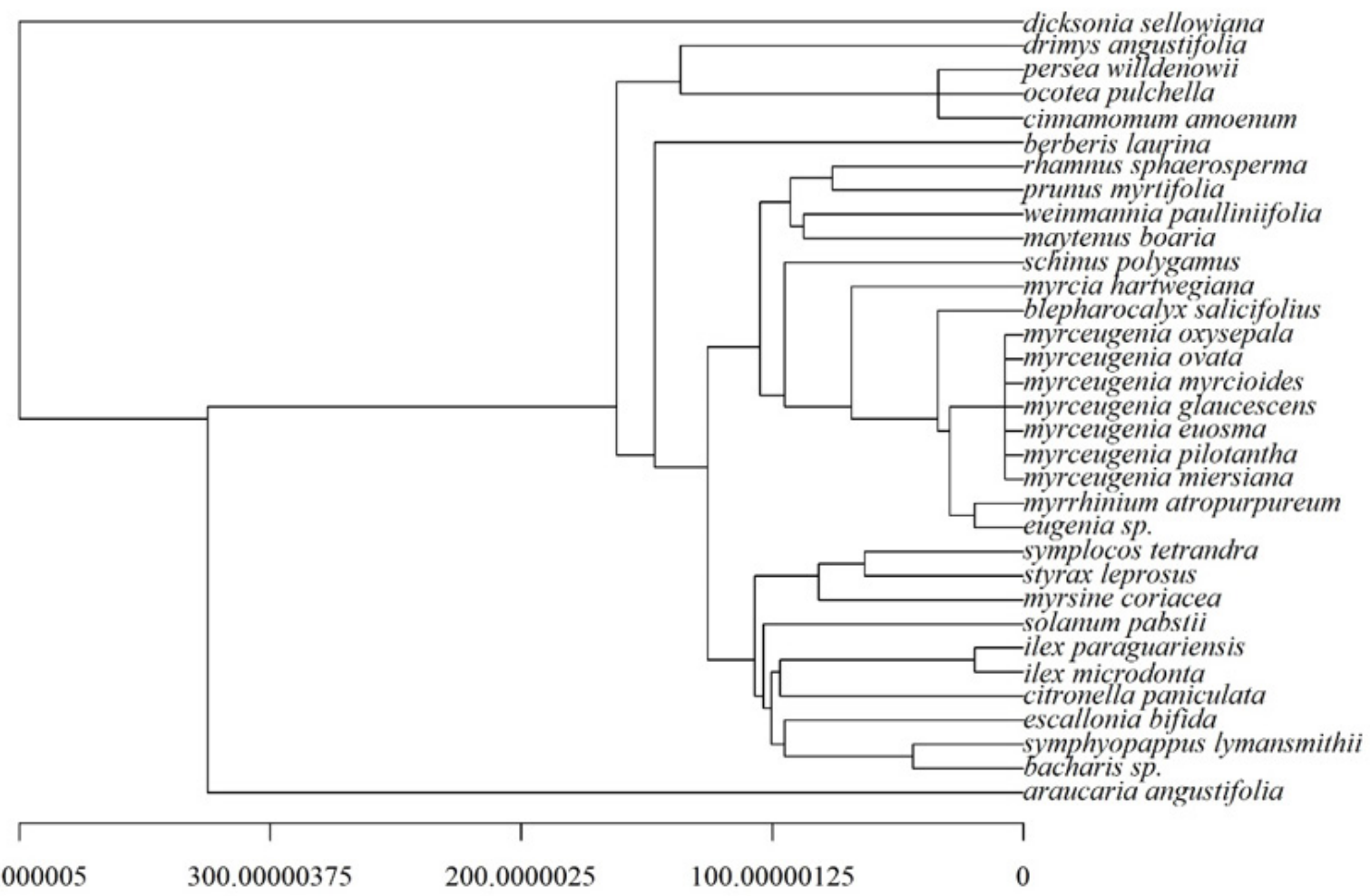

FIGURA 2: Árvore filogenética construída a partir das espécies amostradas em um fragmento de Floresta Nebular no município de Urubici - SC. Escala em milhões de anos.

FIGURE 2: Phylogenetic tree build in function of sampled tree species in a Nebular Forest fragment in the municipality of Urubici, SC state. Scale in millions of years.

como Falkenberg (2003) e Higuchi et al. (2013), também já observaram grande riqueza do gênero em florestas nebulares do Planalto Catarinense. Desta forma, os resultados da literatura e do presente trabalho reforçam a ideia que este gênero sofreu uma rápida e recente radiação na região, a partir de ancestrais de origem andina (MURILLO et al., 2012). De acordo com Linder (2008), este padrão de radiação é típico de paisagens dinâmicas e fragmentadas, o que corrobora com os estudos que indicam eventos de expansão e retração de elementos vegetacionais no Sul do Brasil, em função de flutuações climáticas, com a existência de refúgios em microssítios adequados ao desenvolvimento florestal (BEHLING et al., 2004; CARNAVAL; MORITZ, 2008).

A floresta obteve elevada área basal $\left(42,22 \mathrm{~m}^{2} \cdot \mathrm{ha}^{-1}\right)$ quando comparada com outros estudos em fragmentos florestais na região (e.g. Higuchi et al., 2013, que encontraram $34,80 \mathrm{~m}^{2}$.ha-1 em floresta nebular em Painel - SC). Esse padrão ocorreu devido à presença de árvores com elevada circunferência, denotando uma floresta em avançado estágio de sucessão, e à elevada presença de árvores bifurcadas, sendo que $31,16 \%$ dos indivíduos da comunidade arbórea eram bifurcados e, considerando somente Myrceugenia euosma (O.Berg) D.Legrand, a espécie de maior abundancia (Tabela 1), 42,97\% das árvores eram bifurcadas.

As três espécies de maior representação foram Myrceugenia euosma (VI $=24,51 \%$ ), Ilex microdonta Reissek (VI $=16,85 \%)$ e Dicksonia sellowiana Hook. (VI $=7,68 \%)$. Nas duas primeiras populações, contribuíram para os altos valores de VI a alta densidade dessas espécies (512 e 277 ind.ha $^{-1}$, respectivamente), a presença de árvores de elevada área basal $\left(13,84 \mathrm{e} 10,41 \mathrm{~m}^{2} . \mathrm{ha}^{-1}\right.$, respectivamente) e a frequência de $100 \%$ de ambas nas unidades amostrais. Na terceira população, a elevada densidade da espécie (108 ind.ha $\left.{ }^{-1}\right)$ e a área basal considerável $\left(5,86 \mathrm{~m}^{2} \cdot \mathrm{ha}^{-1}\right)$ foram as variáveis que mais contribuíram para o elevado VI. Somado, os três maiores VIs contribuem com 49,04\% do valor de importância na área, indicando elevada dominância na área estudada. Esse padrão é confirmado pelo valor de Pielou, que indicou elevada dominância ecológica $\left(\mathrm{J}^{\prime}=0,70\right)$. Higuchi et al. (2013) encontraram o mesmo valor para uma 
TABELA 1: Espécies amostradas, ordenadas de forma decrescente pelo valor de importância (VI, em \%) em um fragmento de Floresta Nebular em Urubici - SC.

TABLE 1: Sampled species, sorted by descending order of importance value (VI, in\%) in a Nebular Forest fragment, in the municipality of Urubici, SC state.

\begin{tabular}{|c|c|c|c|c|c|c|c|c|c|c|}
\hline Espécies & Família & $\mathrm{DA}$ & DR & DoA & DoR & FA & FR & VI & $\mathrm{D}$ & $\mathrm{DE}$ \\
\hline $\begin{array}{l}\text { Myrceugenia euosma } \\
\text { (O.Berg) D.Legrand }\end{array}$ & Myrtaceae & 512 & 32,43 & 13,84 & 32,77 & 100 & 8,33 & 24,51 & $\mathrm{Z}$ & $\mathrm{Ag}$ \\
\hline Ilex microdonta Reissek & Aquifoliaceae & 277 & 17,54 & 10,41 & 24,66 & 100 & 8,33 & 16,85 & $\mathrm{Z}$ & $\mathrm{Ag}$ \\
\hline $\begin{array}{l}\text { Dicksonia sellowiana } \\
\text { Hook. }\end{array}$ & Dicksoniaceae & 108 & 6,84 & 5,86 & 13,88 & 28 & 2,33 & 7,68 & An & $\mathrm{Ag}$ \\
\hline Prunus myrtifolia (L.) Urb. & Rosaceae & 82 & 5,19 & 1,56 & 3,69 & 92 & 7,67 & 5,52 & $\mathrm{Z}$ & $\mathrm{Al}$ \\
\hline Drimys angustifolia Miers & Winteraceae & 89 & 5,64 & 1,44 & 3,41 & 84 & 7,00 & 5,35 & $\mathrm{Z}$ & $\mathrm{Ag}$ \\
\hline Ocotea pulchella Mart. & Lauraceae & 69 & 4,37 & 1,40 & 3,32 & 92 & 7,67 & 5,12 & $\mathrm{Z}$ & $\mathrm{Al}$ \\
\hline $\begin{array}{l}\text { Myrceugenia ovata (Hook. } \\
\text { \& Arn.) O.Berg }\end{array}$ & Myrtaceae & 57 & 3,61 & 1,07 & 2,53 & 56 & 4,67 & 3,60 & $\mathrm{Z}$ & $\mathrm{Ag}$ \\
\hline Maytenus boaria Molina & Celastraceae & 43 & 2,72 & 0,90 & 2,13 & 64 & 5,33 & 3,39 & $\mathrm{Z}$ & $\mathrm{Ag}$ \\
\hline $\begin{array}{l}\text { Myrceugenia } \\
\text { oxysepala (Burret) } \\
\text { D.Legrand \& Kausel }\end{array}$ & Myrtaceae & 62 & 3,93 & 0,37 & 0,88 & 60 & 5,00 & 3,27 & $\mathrm{Z}$ & $\mathrm{Ag}$ \\
\hline $\begin{array}{l}\text { Cinnamomum amoenum } \\
\text { (Nees \& Mart.) Kosterm. }\end{array}$ & Lauraceae & 38 & 2,41 & 1,81 & 4,28 & 36 & 3,00 & 3,23 & $\mathrm{Z}$ & $\mathrm{Ag}$ \\
\hline $\begin{array}{l}\text { Weinmannia paulliniifolia } \\
\text { Pohl }\end{array}$ & Cunociaceae & 40 & 2,53 & 0,90 & 2,14 & 40 & 3,33 & 2,67 & An & $\mathrm{Ag}$ \\
\hline $\begin{array}{l}\text { Myrceugenia cf. miersiana } \\
\text { (Gardner) D.Legrand \& } \\
\text { Kausel }\end{array}$ & Myrtaceae & 27 & 1,71 & 0,12 & 0,27 & 64 & 5,33 & 2,44 & $\mathrm{Z}$ & $\mathrm{Al}$ \\
\hline $\begin{array}{l}\text { Symplocos cf. tetrandra } \\
\text { Mart. ex Miq. }\end{array}$ & Symplocaceae & 29 & 1,84 & 0,56 & 1,34 & 44 & 3,67 & 2,28 & $\mathrm{Z}$ & $\mathrm{Ag}$ \\
\hline $\begin{array}{l}\text { Schinus polygamus (Cav.) } \\
\text { Cabrera }\end{array}$ & Anacardiaceae & 20 & 1,27 & 0,17 & 0,41 & 44 & 3,67 & 1,78 & $\mathrm{Z}$ & $\mathrm{Ag}$ \\
\hline $\begin{array}{l}\text { Myrsine coriacea (Sw.) } \\
\text { Roem. \& Schult. }\end{array}$ & Primulaceae & 19 & 1,20 & 0,30 & 0,71 & 36 & 3,00 & 1,64 & $\mathrm{Z}$ & $\mathrm{Ag}$ \\
\hline $\begin{array}{l}\text { Myrceugenia glaucescens } \\
\text { (Cambess.) D.Legrand \& } \\
\text { Kausel }\end{array}$ & Myrtaceae & 18 & 1,14 & 0,09 & 0,20 & 40 & 3,33 & 1,56 & $\mathrm{Z}$ & $\mathrm{Ag}$ \\
\hline $\begin{array}{l}\text { Myrrhinium atropurpureum } \\
\text { Schott }\end{array}$ & Myrtaceae & 19 & 1,20 & 0,24 & 0,57 & 32 & 2,67 & 1,48 & $\mathrm{Z}$ & $\mathrm{Ag}$ \\
\hline $\begin{array}{l}\text { Ilex paraguariensis A.St.- } \\
\text { Hil. }\end{array}$ & Aquifoliaceae & 13 & 0,82 & 0,33 & 0,77 & 32 & 2,67 & 1,42 & $\mathrm{Z}$ & $\mathrm{Al}$ \\
\hline $\begin{array}{l}\text { Myrceugenia myrcioides } \\
\text { (Cambess.) O.Berg }\end{array}$ & Myrtaceae & 16 & 1,01 & 0,17 & 0,41 & 32 & 2,67 & 1,36 & $\mathrm{Z}$ & $\mathrm{Ag}$ \\
\hline $\begin{array}{l}\text { Araucaria angustifolia } \\
\text { (Bertol.) Kuntze }\end{array}$ & Araucariaceae & 8 & 0,51 & 0,19 & 0,44 & 20 & 1,67 & 0,87 & $\mathrm{Z}$ & - \\
\hline $\begin{array}{l}\text { Citronella paniculata } \\
\text { (Mart.) R.A.Howard }\end{array}$ & Cardiopteridaceae & 5 & 0,32 & 0,12 & 0,29 & 16 & 1,33 & 0,65 & $\mathrm{Z}$ & - \\
\hline $\begin{array}{l}\text { Persea cf. willdenowii } \\
\text { Kosterm. }\end{array}$ & Lauraceae & 5 & 0,32 & 0,05 & 0,12 & 12 & 1,00 & 0,48 & $\mathrm{Z}$ & - \\
\hline $\begin{array}{l}\text { Styrax leprosus Hook. \& } \\
\text { Arn. }\end{array}$ & Styracaceae & 3 & 0,19 & 0,08 & 0,19 & 12 & 1,00 & 0,46 & $\mathrm{Z}$ & - \\
\hline $\begin{array}{l}\text { Escallonia bifida Link. \& } \\
\text { Otto }\end{array}$ & Escalloniaceae & 5 & 0,32 & 0,11 & 0,25 & 8 & 0,67 & 0,41 & An & - \\
\hline
\end{tabular}

Continua... 
TABELA 1: Continuação...

TABLE 1: Continued...

\begin{tabular}{|c|c|c|c|c|c|c|c|c|c|c|}
\hline Espécies & & Família & DA & DR & DoA & DoR & FR & VI & $\mathrm{D}$ & $\mathrm{DE}$ \\
\hline $\begin{array}{l}\text { Myrceugenia } \text { cf. pilotantha } \\
\text { (Kiaersk.) Landrum }\end{array}$ & Myrtaceae & 3 & 0,19 & 0,01 & 0,03 & 12 & 1,00 & 0,41 & $\mathrm{Z}$ & - \\
\hline Berberis laurina Billb. & Berberidaceae & 2 & 0,13 & 0,01 & 0,02 & 8 & 0,67 & 0,27 & $\mathrm{Z}$ & - \\
\hline Baccharis sp. & Asteraceae & 2 & 0,13 & 0,01 & 0,01 & 8 & 0,67 & 0,27 & An & - \\
\hline $\begin{array}{l}\text { Symphyopappus cf. } \\
\text { lymansmithii B.L. Rob. }\end{array}$ & Asteraceae & 2 & 0,13 & 0,00 & 0,01 & 8 & 0,67 & 0,27 & An & - \\
\hline $\begin{array}{l}\text { Blepharocalyx salicifolius } \\
\text { (Kunth) O.Berg }\end{array}$ & Myrtaceae & 1 & 0,06 & 0,08 & 0,18 & 4 & 0,33 & 0,19 & $\mathrm{Z}$ & - \\
\hline $\begin{array}{l}\text { Rhamnus sphaerosperma } \\
\text { SW. }\end{array}$ & Rhamnaceae & 2 & 0,13 & 0,01 & 0,03 & 4 & 0,33 & 0,16 & $\mathrm{Z}$ & - \\
\hline Eugenia sp. & Myrtaceae & 1 & 0,06 & 0,01 & 0,02 & 4 & 0,33 & 0,14 & $\mathrm{Z}$ & - \\
\hline $\begin{array}{l}\text { Solanum pabstii L.B.Sm. } \\
\text { \& Downs }\end{array}$ & Solanaceae & 1 & 0,06 & 0,00 & 0,01 & 4 & 0,33 & 0,13 & $\mathrm{Z}$ & - \\
\hline $\begin{array}{l}\text { Myrcia } \\
\text { hartwegiana (O.Berg) } \\
\text { Kiaersk. }\end{array}$ & Myrtaceae & 1 & 0,06 & 0,00 & 0,01 & 4 & 0,33 & 0,13 & Z & - \\
\hline Total & & 1579 & 100,0 & 42,22 & 100,0 & 1200 & 100,0 & 100,0 & - & - \\
\hline
\end{tabular}

Em que: DA: densidade absoluta (ind.ha $\left.{ }^{-1}\right)$; DR: densidade relativa (\%); DoA: dominância absoluta $\left(\mathrm{m}^{2}\right.$.ha $\left.{ }^{-1}\right)$; DoR: dominância relativa (\%); FA: frequência absoluta (\%); FR: frequência relativa (\%); D: síndrome de dispersão de propágulo, sendo $\mathrm{Z}$ a dispersão zoocórica e $\mathrm{An}$ a dispersão anemocórica; $\mathrm{DE}$ : distribuição espacial, sendo $\mathrm{Ag}$ a distribuição agregada e $\mathrm{Al}$ a distribuição aleatória.

floresta nebular em Painel, considerando também como dominância relativamente alta. Esse é um padrão esperado em florestas que possuem um ou mais fatores seletivos. Nesse caso, o frio intenso, associado aos fatores advindos de sua influência, são os mais atuantes na seletividade das espécies na área e definidores da alta dominância.

A síndrome de dispersão predominante foi a zoocoria (28 espécies, representando 84,85\%), seguida pela anemocoria (cinco espécies, representando 15,15\%). Espécies arbóreas zoocóricas têm sido predominantes em florestas tropicais (MORELLATO; LEITÃO FILHO, 1992; TABARELLI et al., 1999; TALORA; MORELLATO, 2000; NUNES et al., 2003; YAMAMOTO et al., 2007; CARVALHO, 2010; STEFANELLO et al., 2010) e subtropicais (ALBERTI et al., 2000; NASCIMENTO et al., 2000; BUDKE et al., 2005; GIEHL et al., 2007; RUSCHEL et al., 2007), confirmando a importância dos animais para a dispersão de propágulos. As síndromes de distribuição de propágulos normalmente estão relacionadas a famílias botânicas ou grupos de espécies, sendo possível observar, no presente estudo, família de grande riqueza de espécies, como Myrtaceae, com todas as espécies amostradas zoocóricas. Foram anemocóricas somente Dicksonia sellowiana Hook., uma pteridófita que possui os esporos dispersos pelo vento, e quatro espécies de angiospermas: Weinmannia paulliniifolia Pohl, Escallonia bifida Link. \& Otto e as Asteraceae Baccharis sp. e Symphyopappus cf. lymansmithii B.L. Rob.

A distribuição espacial foi predominantemente agregada, com 15 populações com essa distribuição (78,95\% das populações em que foi possível determinar a distribuição). As demais, compostas por quatro populações, possuem distribuição aleatória $(21,05 \%)$. Nenhuma das populações teve distribuição regular. Esses resultados confirmam o estudo de Nascimento et al. (2001) que, em um fragmento de Floresta Ombrófila Mista em Nova Prata - RS, também encontraram predominância de espécies com distribuição espacial agregada, e contrastam com o resultado de Negrini et al. (2012) que, estudando a mesma fitofisionomia em Lages - SC, encontraram predominância de distribuição aleatória. Assim, é possível perceber que, na Floresta Ombrófila Mista, não há um padrão quanto às distribuições espaciais, podendo 
estas estar relacionadas às variações ambientais, diferenças florísticas e histórico de perturbação das áreas. Embora Negrini et al. (2012) tenham encontrado a zoocoria associada à distribuição aleatória, no presente estudo, em concordância com outros autores (HARMS et al., 2000; JORDANO; GODOY, 2002; GIEHL et al., 2007), a zoocoria esteve mais associada à distribuição agregada (maioria das zoocóricas obtiveram distribuição agregada), sendo atribuído, por esses mesmos autores, ao fato dos diásporos serem depositados em lugares específicos, nos quais os animais permanecem por mais tempo.

Nas parcelas, em média, os valores de MPD, ou seja, a distância filogenética de dois indivíduos amostrados aleatoriamente, foi de 232,7 milhões de anos, variando de 117,3 a 442,9 milhões de anos. A maioria das parcelas obteve seus valores de MPD entre 150 e 200 milhões de anos (Figura 3A). Os valores de NRI variaram de $-3,13$ a 1,14, sendo a maioria das parcelas encontradas entre 0 e 1 (Figura 3B). Apenas as parcelas presentes nas classes inferiores a -3 apresentaram sobredispersão filogenética significativa ( $p$ $\leq 0,05)$, ou seja, indivíduos distantes filogeneticamente. Nas demais parcelas, a estrutura filogenética não diferiu do modelo nulo de completa aleatoriedade $(p>0,05)$. Willis et al. (2010) também observaram a predominância de ausência de estruturação filogenética em pequenas escalas espaciais. De acordo os autores, a ocorrência de agrupamento filogenético é mais frequente em função do incremento de variações ambientais.
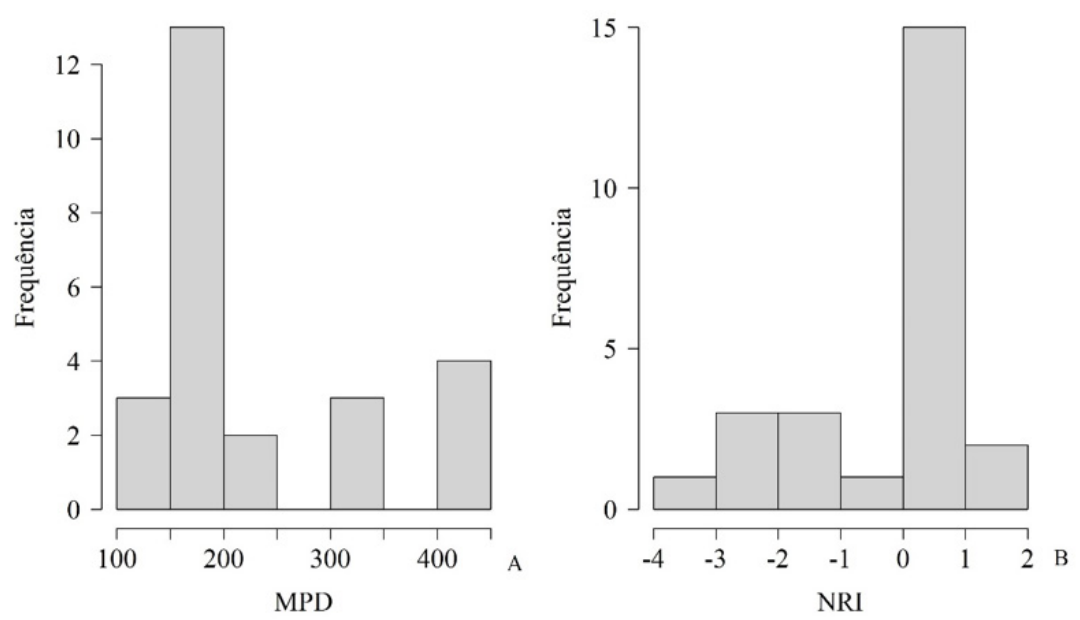

FIGURA 3: Distribuição dos valores de "Mean pairwise distance (MPD)" (A) e de "Net Relatedness Index” (NRI) (B) em parcelas $(20 \times 20$ m) de um fragmento de Floresta Nebular no município de Urubici - SC.

FIGURE 3: Value distribution of the "Mean pairwise distance (MPD)" (A) and "Net relatedness Index" (NRI) (B) in sampling plots $(20 \times 20 \mathrm{~m})$ in a fragment of Nebular Forest in the municipality of Urubici, SC state.

Apesar de a organização filogenética das espécies na maior parte das parcelas ocorrer de forma aleatória $(p>0,05)$, observou-se a estruturação espacial das métricas analisadas, com autocorrelação positiva em uma escala de até aproximadamente $70 \mathrm{~m}$ e autocorrelação negativa a uma distância aproximada de 170 $\mathrm{m}$ (Figura 4). Estes resultados indicam que, em pequena escala espacial, a estrutura filogenética de uma comunidade pode não ocorrer de forma homogênea, como no presente caso, podendo apresentar variações espaciais, que podem ser uma resposta à complexa interação entre diferentes fatores ecológicos. Nas parcelas com dispersão filogenética, pode-se inferir que fatores que controlam a densidade populacional de indivíduos coespecíficos ou filogeneticamente próximos entre si (e.g. competição inter e intraespecifica, predação, herbivoria) podem estar atuando como maior intensidade (KEMBELL; HUBBELL, 2006). Já o padrão aleatório, que ocorreu na maioria das parcelas, pode indicar a interação neutra entre as espécies e/ou equilíbrio entre processos ecológicos determinantes (KEMBELL; HUBBELL, 2006). 

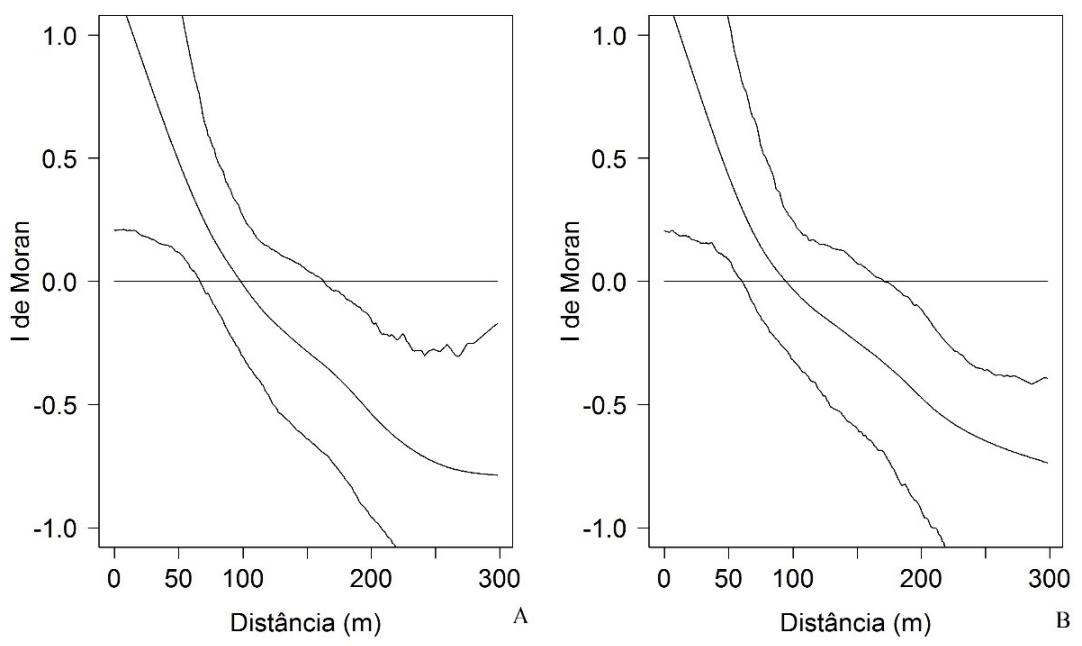

FIGURA 4: Correlogramas de I de Moran com alisamento por spline, com os respectivos envelopes de completa aleatoriedade construídos por meio de bootstrap, a partir de 1.000 reamostragens, para as MPD (A) e NRI (B) em um fragmento de Floresta Nebular no município de Urubici SC. Os valores de I Moran variam de -1 a 1, os valores positivos indicam associação espacial positiva entre os locais (similaridade) e valores negativos indicam associação negativa (dissimilaridade). Valores em torno de 0, dentro dos envelopes de completa aleatoriedade, indicam distribuição aleatória sem associação espacial.

FIGURE 4: I Moran correlograms with spline smoothing, with the respective envelopes indicating complete randomness, built by bootstrap considering 1000 resampling, for MPD (A) and NRI (B) in a Nebular Forest in the municipality of Urubici, SC state. Moran I values range from -1 to 1 , positive values indicate positive spatial association between the sites (similarity) and negative values indicate negative association (dissimilarity). Values around 0 , within the envelopes of complete randomness, indicate random distribution without spatial association.

\section{CONCLUSÕES}

As espécies arbóreas amostradas indicam elementos florísticos característicos de uma Floresta Nebular, com grande riqueza de espécies de Myrceugenia. Porém, é possível perceber a influência de espécies típicas da Floresta Ombrófila Mista, como Araucaria angustifolia. A estrutura, com elevada dominância ecológica, era esperada para esse tipo de formação vegetacional, sujeita a condições limitantes do ambiente, como o frio intenso e a baixa radiação solar devido à alta nebulosidade.

A síndrome de dispersão de propágulos predominante foi a zoocoria, padrão comum em florestas tropicais e subtropicais, assim como na Floresta Ombrófila Mista. Dessa forma, a manutenção de animais na floresta é fundamental para sua sobrevivência ao longo do tempo. Quando se pensa em conservação, portanto, deve-se considerar a preservação de todo o ecossistema, com sua biodiversidade associada. A distribuição espacial predominante foi a agregada, com poucas populações apresentando a distribuição aleatória. A síndrome de dispersão zoocórica esteve associada, neste estudo, à distribuição agregada.

A comunidade apresentou variação em relação à estruturação filogenética, sendo que na maioria das parcelas o padrão não diferiu do modelo nulo de completa aleatoriedade. Essa variação pode ser interpretada como uma resposta à complexa interação entre os diferentes fatores ecológicos (e.g. filtro ambiental e competição) que moldam a estrutura da comunidade de espécies arbóreas. 


\section{AGRADECIMENTOS}

Ao CNPq, pela concessão de bolsa de produtividade em pesquisa ao primeiro e ao segundo autor.

\section{REFERÊNCIAS}

AGUIAR, M. D. et al. Potencial de uso de espécies arbóreas de uma floresta secundária em Lages, Santa Catarina. Revista de Ciências Agroveterinárias, Lages, v. 11, n. 3, p. 238-247, 2012.

ALBERTI, L. F. et al. Aspectos florísticos e síndromes de dispersão das espécies arbóreas do Morro de Santo Antão, Santa Maria-RS. Ciência e Natura, Santa Maria, v. 22, n. 1, p. 145-160, 2000.

ALMEIDA, S. R. et al. Florística e síndromes de dispersão de um remanescente de Floresta Ombrófila Mista em sistema faxinal. Ambiência, Guarapuava, v. 4, n. 2, p. 289-297, 2008.

ANGIOSPERM PHYLOGENY GROUP. An update of the Angiosperm Phylogeny Group classification for the orders and families of flowering plants: APG III. Botanical Journal of the Linnean Society, London, v. 161, n. 2, p. 105-121, 2009.

BEHLING, H. et al. Quaternary Araucaria forest, grassland (Campos), fire and climate dynamics, studied by high-resolution pollen, charcoal and multivariate analysis of the Cambará do Sul core in southern Brazil.

Palaeogeography, Palaeoclimatology, Palaeoecology, Amsterdam, v. 203, n. 3-4, p. 277-297, 2004.

BUDKE, J. C. et al. Composição florística e estratégias de dispersão de espécies lenhosas em uma floresta ribeirinha, arroio Passo das Tropas, Santa Maria, RS, Brasil. Iheringia, Série Botânica, Porto Alegre, v. 60 , n. 1, p. 17-24, 2005.

CARNAVAL, A. C.; MORITZ, C. Historical climate modelling predicts patterns of current biodiversity in the Brazilian Atlantic forest. Journal of Biogeography, Hoboken, v. 35, n. 7, p. 1187-1201, 2008.

CARVALHO, F. A. Síndromes de dispersão de espécies arbóreas de florestas ombrófilas submontanas do estado de Rio de Janeiro. Revista Árvore, Viçosa, MG, v. 34, n. 6, p. 1017-1023, 2010.

CAVENDER-BARES, J. et al. The merging of community ecology and phylogenetic biology. Ecology Letters, Montpellier, v. 12, n. 7, p. 693-715, 2009.

COWEL, R. K. et al. Global warming, elevation range shift, and lowland biotic atrition in the wet tropics. Science, New York, v. 322, n. 5899, p. 258-261, 2008.

ESKUCHE, U. El bosque de Araucaria con Podocarpus y los campos de Bom Jardim da Serra, Santa Catarina (Brasil meridional). Boletín de la Sociedad Argentina de Botánica, Córdoba, v. 42, n. 3-4, p. 295-308, 2007.

FALKENBERG, D. Matinhas nebulares e vegetação rupícola dos Aparados da Serra Geral (SC/RS), sul do Brasil. 2003. 558 f. Tese (Doutorado em Biologia Vegetal) - Universidade Estadual de Campinas, Campinas.

FORMENTO, S. et al. Dinâmica estrutural arbórea de uma Floresta Ombrófila Mista em Campo Belo do Sul, SC. Cerne, Lavras, MG, v. 10, n. 2, p. 196-212, 2004.

GASTAUER, M.; MEIRA NETO, J. A. A. Avoiding inaccuracies in tree calibration and phylogenetic community analysis using Phylocom 4.2. Ecological Informatics, Amsterdam, v. 15, p. 85-90, 2013.

GIEHL, E. L. H. et al. Espectro e distribuição vertical das estratégias de dispersão de diásporos do componente arbóreo em uma floresta estacional no sul do Brasil. Acta Botanica Brasilica, Feira de Santana, v. 21, n. 1, p. 137-145, 2007.

HARDY, O. J. Testing the spatial phylogenetic structure of local communities: statistical performances of different null models and test statistics on a locally neutral community. Journal of Ecology, London, v. 96, n. 5, p. 914-926, 2008.

HARMS, K. E. et al. Pervasive density-dependent recruitment enhances seedling diversity in a tropical forest. Nature, London, v. 404, n. 6777, p. 493-495, 2000.

HIGUCHI, P. et al. Floristic composition and phytogeography of the tree component of Araucaria Forest fragments in southern Brazil. Brazilian Journal of Botany, São Paulo, v. 35, n. 2, p. 145-157, 2012a.

HIGUCHI, P. et al. Influência de variáveis ambientais sobre o padrão estrutural e florístico do componente arbóreo, em um fragmento de Floresta Ombrófila Mista Montana em Lages, SC. Ciência Florestal, Santa Maria, v. 22, n. 1, p. 79-90, 2012 b. 
HIGUCHI, P. et al. Florística e estrutura do componente arbóreo e análise ambiental de um fragmento de Floresta Ombrófila MistaAlto-montana no município de Painel, SC. Ciência Florestal, Santa Maria, v. 23,n. 1, p. 153-164, 2013.

HIJMANS, R. J. et al. Very high resolution interpolated climate surfaces for global land areas. International Journal of Climatology, Hoboken, v. 25, p. 1965-1978, 2005.

IBGE. Manual técnico da vegetação brasileira. Rio de Janeiro: Fundação Instituto Brasileiro de Geografia e Estatística, 2012. 271 p. (Manuais Técnicos em Geociências, n. 1).

INTERGOVERNMENTAL PANEL ON CLIMATE CHANGE. Climate Change 2007: synthesis report. Geneva: Switzerland, 2007. 104 p.

JARENKOW, J. A.; BAPTISTA, L. R. M. Composição florística e estrutura da mata com araucária na Estação Ecológica de Aracuri, Esmeralda, Rio Grande do Sul. Napaea, Porto Alegre, v. 3, p. 9-18, 1987.

JORDANO, P.; GODOY, J. A. Frugivore-generated seed shadows: a landscape view of demographic and genetic effects. In: LEVEY, D. J. et al. Seed dispersal and frugivory: ecology, evolution and conservation. New York: CABI Publishing, 2002. p. 305-321.

KEMBELL, S. W.; HUBBELL, S. P. The phylogenetic structure of a neotropical forest tree community. Ecology, Ithaca, v. 87, n. 7 supl., p. S86-S99, 2006.

KLAUBERG, C. et al. Florística e estrutura de um fragmento de Floresta Ombrófila Mista no Planalto Catarinense. Biotemas, Florianópolis, v. 23, n. 1, p. 35-47, 2010.

KLEIN, R. M. Mapa fitogeográfico de Santa Catarina. In: REITZ, R. Flora Ilustrada de Santa Catarina. Itajaí: Herbário Barbosa Rodrigues, 1978. p. 1-24.

KOEHLER, A. et al. Floresta Ombrófila Densa Altomontana: aspectos florísticos e estruturais de diferentes trechos da serra do mar. Ciência Florestal, Santa Maria, v. 12, n. 2, p. 27-39, 2002.

LEYSER, G. et al. Espectro de dispersão em um fragmento de transição entre Floresta Ombrófila Mista e Floresta Estacional na região do Alto Uruguai, Rio Grande do Sul, Brasil. Pesquisas, Série Botânica, São Leopoldo, v. 60, p. 355-366, 2009.

LINDER, H. P. Plants species radiations: where, when and why? Philosofical Transactions of the Royal Society B, Londres, v. 363, n. 1506, p. 3097-3105, 2008.

MARCON, A. K. et al. Variação florístico-estrutural em resposta à heterogeneidade ambiental em uma Floresta Nebular em Urubici, Planalto Catarinense. Scientia Forestalis, Piracicaba, v. 42, n. 103, p. 439-450, 2014.

MORAN, P. A. P. Notes on continuous stochastic phenomena. Biometrika, Oxford, v. 37, n. 1-2, p. 17-23, 1950.

MORELlATO, L. P. C.; LEITÃO FILHO, H. F. Padrões de frutificação e dispersão da Serra do Japi. In:

História Natural da Serra do Japi: ecologia e preservação de uma área florestal no Sudeste do Brasil. Campinas: Editora da UNICAMP/FAPESP, 1992. p. 112-141.

MORISITA, M. Id-index, a measure of dispersion of individuals. Researches on Population Ecology, Kyoto, v. 4, n.1, p. 1-7, 1962.

MULLER-DOMBOIS, D.; ELLENBERG, H. Aims and of vegetation ecology. New York: John Wiley \& Sons, 1974. $547 \mathrm{p}$.

MURILLO, J. et al. Phylogenetic relationships in Myrceugenia (Myrtaceae) based on plastid and nuclear DNA sequences. Molecular Phylogenetics and Evolution, Amsterdam, v. 62, n. 2, p. 764-776, 2012.

NASCIMENTO, A. R. T. et al. Análise da diversidade florística e dos sistemas de dispersão de sementes em um fragmento florestal da região central do Rio Grande do Sul, Brasil. Napaea, Porto Alegre, v. 12, p. 49-67, 2000.

NASCIMENTO, A. R. T. et al. Estrutura e padrões de distribuição espacial de espécies arbóreas em uma amostra de Floresta Ombrófila Mista em Nova Prata, RS. Ciência Florestal, Santa Maria, v. 11, n. 1, p. 105-119, 2001.

NASCIMENTO, A. R. T. et al. Estrutura e classificação de um remanescente de floresta ripária no município de Lages, SC. Ciência Florestal, Santa Maria, v. 21, n. 2, p. 209-218, 2011.

NEGRINI, M. et al. Dispersão, distribuição espacial e estratificação vertical da comunidade arbórea em um fragmento florestal no Planalto Catarinense. Revista Árvore, Viçosa, v. 36, n. 5, p. 919-930, 2012.

NUNES, Y. R. F. N. et al. Variações da fisionomia, diversidade e composição de guildas da comunidade 
arbórea em um fragmento de floresta semidecidual em Lavras, MG. Acta Botânica Brasilica, Feira de Santana, v. 17, n. 2, p. 213-229, 2003.

OKSANEN, J. et al. Vegan: community ecology package. R package version, 2009. v. 1, p. 8.

R CORE TEAM. R: a language and environment for statistical computing. Vienna: R Foundation for Statistical Computing, 2012. Disponível em: <http://www.R-project.org>. Acesso em: 18 nov. 2012.

RONDON NETO, R. M. et al. Diversidade florística e síndromes de dispersão de diásporos das espécies arbóreas de um fragmento de Floresta Ombrófila Mista. Revista Ciências Exatas e Naturais, Guarapuava, v. 3, n. 2, p. 167-175, 2001.

RUSCHEL, A. R.; NODARI, R. O.; MOERSCHBACHER, B. M. Woody plant species richness in the Turvo State park, a large remnant of deciduous Atlantic forest, Brazil. Biodiversity and Conservation, Ney York, v. 16, n. 6, p. 1699-1714, 2007.

SILVA, A. C. et al. Relações florísticas e fitossociologia de uma Floresta Ombrófila Mista Montana secundária em Lages, Santa Catarina. Ciência Florestal, Santa Maria, v. 22, n. 1, p. 193-206, 2012.

SILVA, A. C. et al. Caracterização fitossociológica e fitogeográfica de um trecho de floresta ciliar em Alfredo Wagner, SC, como subsídio para restauração ecológica. Ciência Florestal, Santa Maria, v. 23, n. 4, p. 579-593, 2013.

SMITH-GILL, S. J. Cytophysiological basis of disruptive pigmentary patterns in the leopard frog, Rana pipiens. II. Wild type and mutant cell specific patterns. Journal of Morphology, Hoboken, v. 146, n. 1, p. 35-54, 1975.

SOUZA, V. C.; LORENZI, H. Botânica Sistemática: guia ilustrado para identificação das famílias de Angiospermas da flora brasileira, baseado em APG II. Nova Odessa: Instituto Plantarum, 2005. 640 p.

STEFANELLO, D. et al. Síndromes de dispersão de diásporos das espécies de trechos de vegetação ciliar do rio das Pacas, Querência - MT. Acta Amazonica, Manaus, v. 40, n. 1, p. 141-150, 2010.

TABARELLI, M. et al. Effects of habitat fragmentation on plant guild structure in the montane Atlantic forest of southeastern Brazil. Biological Conservation, Amsterdam, v. 91, v. 2-3, p. 119-127, 1999.

TALORA, D. C.; MORELLATO, L. P. C. Fenologia de espécies arbóreas em floresta de planície litorânea do sudeste do Brasil. Revista Brasileira de Botânica, São Paulo, v. 23, n. 1, p. 13-26, 2000.

VAN DER PIJL, L. Principles of dispersal in higher plants. Berlim: Springer-Verlag. 1982. 162 p.

WEBB, C. O. Exploring the phylogenetic structure of ecological communities: an example for rain forest trees. The American Naturalist, Chicago, v. 156, n. 2, p. 145-155, 2000.

WEBB, C. O. et al. Phylogenies and Community Ecology. Annual Review of Ecology and Systematics, Palo Alto, v. 33, p. 475-505, 2002.

WEBB, C. O. et al. Phylocom: software for the analysis of phylogenetic community structure and trait evolution. Bioinformatics, Oxford, v. 24, n. 18, p. 2098-2100, 2008.

WEBB, C. O.; DONOGHUE, M. J. Phylomatic: tree assembly for applied phylogenetics. Molecular Ecology Note, Hoboken, v. 5, n. 1, p. 181-183, 2004.

WIKSTRÖM, N. et al. Evolution of the angiosperms? calibrating the family tree. Proceedings of the Royal Society B Biological Science, London, v. 268, n. 1482, p. 2211-2220, 2001.

WILLIS, C. G. et al. Phylogenetic community structure in Minnesota oak savanna is influenced by spatial extent and environmental variation. Ecography, Hoboken, v. 33, n. 3, p. 565-577, 2010.

YAMAMOTO, L. F. et al. Síndrome de polinização e de dispersão em fragmentos da Floresta Estacional Semidecídua Montana, SP, Brasil. Acta Botância Brasilica, Feira de Santana, v. 21, n. 3, p. 553-573, 2007. ZAR, J. K. Biostatistical analysis. New Jersey: Prentice Hall. 1996. 718 p. 